\title{
Leptospira in breast tissue and milk of urban Norway rats (Rattus norvegicus)
}

\author{
D. DE OLIVEIRA ${ }^{1}$, C. P. FIGUEIRA ${ }^{1}$, L. ZHAN ${ }^{2}$, A. C. PERTILE ${ }^{1}$, \\ G. G. PEDRA ${ }^{1}$, I. M. GUSMÃO ${ }^{1}$, E. A. WUNDER JR. ${ }^{2}$, G. RODRIGUES ${ }^{3}$, \\ E. A. G. RAMOS ${ }^{1}$, A. I. KO ${ }^{1,2}$, J. E. CHILDS ${ }^{2}$, M. G. REIS ${ }^{1,2,4}$ AND \\ F. $\operatorname{COSTA}^{1,2,5 *}$ \\ ${ }^{1}$ Centro de Pesquisas Gonçalo Moniz, Fundação Oswaldo Cruz, Ministério da Saúde, Salvador, Brazil \\ ${ }^{2}$ Department of Epidemiology of Microbial Disease, Yale School of Public Health, New Haven, CT, USA \\ ${ }^{3}$ Centro de Controle de Zoonoses, Secretaria Municipal de Saúde, Ministério da Saúde, Salvador, Brazil \\ ${ }^{4}$ Faculdade de Medicina, Universidade Federal da Bahia, UFBA, Salvador, Brazil \\ ${ }^{5}$ Instituto de Saúde Coletiva, Universidade Federal da Bahia, UFBA, Salvador, Brazil
}

Received 8 January 2016; Final revision 5 March 2016; Accepted 6 March 2016;

first published online 28 March 2016

\section{SUMMARY}

Leptospirosis is a zoonosis caused by bacteria of the genus Leptospira. The disease is globally distributed and a major public health concern. The Norway rat (Rattus norvegicus) is the main reservoir of the pathogen in urban slums of developing and developed countries. The potential routes of intra-specific leptospire transmission in rats are largely unknown. Herein, we identified pathogenic Leptospira spp. in breast tissue and milk of naturally infected rats. We examined kidney, breast tissue and milk from 24 lactating rats for the presence of leptospires using immunofluorescence, immunohistochemistry, polymerase chain reaction (PCR) and scanning electronic microscopy. All 24 rats had evidence for Leptospira in the kidneys, indicating chronic carriage. The majority of kidneypositive rats had detectable leptospires in milk $(18,75 \%)$ and breast tissue $(16,67 \%)$, as evidenced by immunofluorescence assay and immunohistochemistry. Four (17\%) milk samples and two (8\%) breast tissue samples were positive by quantitative real-time PCR. Scanning electron microscopy confirmed the presence of leptospires in breast tissue. No major pathological changes in breast tissue were found. This study, for the first time, identified leptospires in the milk and breast tissue of wild Norway rats, suggesting the possibility of milk-borne transmission of leptospirosis to neonates.

Key words: Breastfeeding, immunofluorescence, immunohistochemistry, Rattus norvegicus, scanning electronic microscopy, vertical transmission.

\section{INTRODUCTION}

Leptospirosis is a globally distributed zoonosis caused by bacteria of the genus Leptospira [1]. This disease has a large impact on public health, accounting for

\footnotetext{
* Author for correspondence: Dr F. Costa, Adjunct Professor, Instituto de Saúde Coletiva, Universidade Federal da Bahia, UFBA, Salvador, Brazil, 40·110-040.

(Email: federico.costa@ufba.br)
}

at least one million annual human cases worldwide [2]. Leptospirosis can be transmitted through direct contact with the urine of infected animals and occasionally through rodent bites [3], and indirectly by exposure to water or soil contaminated with leptospires excreted in the urine of infected hosts $[1,4,5]$. The burden of disease in developing countries is associated with residents of urban slums, as exemplified by studies conducted in Salvador, Brazil, where outbreaks 
during the rainy season affect the poorest proportion of the population [6-8].

The Norway rat, Rattus norvegicus, is the primary reservoir for pathogenic leptospires in the slums of Brazil $[9,10]$ and in many urban centres in developing and developed countries [11-14]. Despite studies describing the prevalence of Leptospira infection in Norway rats in Salvador, Brazil, [10, 15], little is known about the maintenance and intra-specific transmission of this pathogen within rat populations [13].

Although environmental transmission is possibly the major route for Leptospira infection in rodents [16], a recent study indicated that young nonreproductive rats, which had just left the nest, showed a prevalence of up to $30 \%$ of kidney colonization [15]. Infection at a very young age ( $>2$ months) suggests that transmission may occur also in utero or to neonates, possibly through infectious milk, or by other routes within the nest including close contact with an infected mother via fomites or uro-gentital cleansing of neonates by the dam. While intrauterine transmission of leptospires has been documented for humans [17, 18], and occurs in horses [19], there has been only a single case report of breastfeedingassociated transmission in humans [20]. There has also been just a single case report of sexual transmission in humans [21], but is likely in horses, based on findings of leptospiral DNA in semen [22]. Transplacental transmission of leptospires is well recognized in livestock animals (and is related to abortions) [19, 23, 24]; however, there is no clear evidence of this route of transmission in rodent populations [25-27].

Herein we report the presence of Leptospira spp. in breast tissue and milk indicating the potential for neonatal transmission in $R$. norvegicus. Our results will inform predictive models of intra-specific maintenance and transmission of leptospires in rodents [28] to better understand and generate new hypotheses regarding the contribution of varied routes of transmission in reservoir populations.

\section{METHODS}

\section{Study site}

Norway rats ( $R$. norvegicus) were trapped at the study area of Pau da Lima $\left(0 \cdot 16 \mathrm{~km}^{2}\right)$ in the coastal city of Salvador, Brazil $[6,29]$. High human density $(>3700$ inhabitants $/ 0 \cdot 16 \mathrm{~km}^{2}$ ); low socioeconomic level and lack of basic sanitation and garbage collection are features of this area [30]. Prospective cohort studies performed in this setting since 2003 have identified an incidence of leptospiral infection of $36 / 1000$ person-years $[6,29]$.

\section{Trapping of rats and sample collection}

Norway rats were trapped from peridomestic areas in Pau da Lima. Double-bagged traps containing rats were transported to the Zoonotic Control Centre (ZCC) and animals were euthanized following protocols previously described [15]. Only lactating females were selected for this study. After euthanasia and hair removal in the ventral region, the whole body of lactating rats was cleansed with $70 \%$ alcohol. Milk was extracted by finger pressure applied to each breast, generally collected from the most enlarged breasts. Small drops $(\sim 10-20 \mu \mathrm{l})$ of milk were expressed onto poly-L-lysine-coated glass slides for indirect immunofluorescence assay (IFA) and 1-2 small drops collected by sterile swab swipes and stored at $-80^{\circ} \mathrm{C}$ for quantitative real-time polymerase chain reaction (qPCR). Breast tissue samples were cut from the muscle base and the exposed surface was pressed on glass slides for IFA testing. Five left breast tissue samples were collected and fixed in $10 \%$ neutral buffered formalin for immunohistochemistry (IHC). Breast tissue from four animals was separated for scanning electronic microscopy (SEM) and seven breast tissue samples were collected to attempt isolation of Leptospira. Breast tissue from two healthy and non-infected lactating laboratory rats ( $R$. norvegicus Wistar) was used as negative controls in all experiments.

To document chronic leptospiral carriage kidneys were obtained from all animals and tested as described previously [31]. It is important to note that chronic kidney carriage occurs after leptospiral systemic infection is cleared from multiple tissues and blood indicating that any further identification of leptospires in other tissues is indicative of prolonged infection in additional sites.

All animal protocols were approved by the Institutional Animal Care and Use Committee (IACUC) at the Oswaldo Cruz Foundation (Salvador, Brazil; 03/ 2012) and Yale University (New Haven, CT; 2012$11498)$.

\section{IFA}

Slides with imprints of kidney, breast tissue and milk were analysed by IFA as described previously [32]. Briefly, slides were fixed in acetone for $3 \mathrm{~min}$ and 
then washed with phosphate-buffered saline (PBS). Blocking with $1 \%$ bovine serum albumin (BSA) for 40 min was followed by 1-h incubation with hyperimmune rabbit antisera to whole $L$. interrogans serovar Icterohaemorrhagiae strain RGA diluted 1:1000 [32, 33]. After drying, the samples were fixed in acetone for $3 \mathrm{~min}$ and re-washed with PBS. Samples from non-infected laboratory rats were similarly treated as negative controls. Additional negative controls were generated from kidney-positive wild rats by incubating slides with normal rabbit serum at the same dilution. After washing with PBS, the imprints were incubated with goat anti-rabbit IgG Alexa 488 (Invitrogen, USA) at a dilution of 1:500 for $1 \mathrm{~h}$. The imprints were washed $3 \times$ with PBS, mounted with anti-fading medium (ProLong Molecular Probes, Thermo Fisher Scientific, USA) and examined at $\times 400$ and $\times 1000$ (Olympus BX51 microscope, Olympus America, USA). We estimated the presence of leptospires in milk imprint as the mean number of leptospires per four fields of view at a magnification of $\times 1000$.

\section{IHC}

Fragments of the breast tissue used for imprints were fixed in $10 \%$ formalin, embedded in paraffin according to routine histological procedures and cut into 4-5 $\mu \mathrm{m}$ sections. Sections were stained with haematoxylin and eosin (H\&E) for histopathological analyses. Paraffin was removed with xylene and ethanol. Following the methodology described previously [32], slides were treated with $3 \%$ hydrogen peroxide for $15 \mathrm{~min}$ at room temperature, blocked with $1 \% \mathrm{BSA}$ and then incubated at $37^{\circ} \mathrm{C}$ for $1 \mathrm{~h}$ with a 1:2000 dilution of pathogen-specific rabbit antiserum against LipL32 [34]. After three washes with PBS, slides were incubated with biotinylated-conjugated anti-rabbit immunoglobulin and then with horseradish peroxidaseconjugated streptavidin (Invitrogen). The chromogen used (3,3-diaminobenzidine; DAB; Invitrogen kit 00-2114) was visualized as a brown deposit. Finally, the slides were stained with haematoxylin, mounted with balsam and cover-slipped. Positive kidney samples from wild rats were processed identically and used as positive controls. Slides were examined in brightfield microscopy (Olympus BX51, at $\times 1000$ ).

\section{Culture isolation}

Breast tissue samples were macerated and inoculated into $5 \mathrm{ml}$ liquid EMJH medium [35]. The cultures were incubated at $29^{\circ} \mathrm{C}$ for $24 \mathrm{~h}$. After this period, $0.5 \mathrm{ml}$ supernatant was subcultured in another tube with $5 \mathrm{ml}$ EMJH medium. The cultures were examined weekly over 3 months by darkfield microscopy. In case of contamination by other microorganisms, filtering methodologies were attempted using $0.22 \mu \mathrm{l}$ pore syringe filters (Sterile Millipore, Millipore Corp., USA).

\section{SEM}

Breast tissue samples were cut into $1-2 \mathrm{~mm}$ pieces and fixed in $2.5 \%$ glutaraldehyde and $0.1 \mathrm{~m}$ sodium cacodylate buffer $(\mathrm{pH} 7 \cdot 4)$. Samples were post-fixed with $1 \%$ osmium tetroxide for $1 \mathrm{~h}$, washed with $0 \cdot 1 \mathrm{~m}$ sodium cacodylate buffer, dehydrated in a series of ethanol baths and dried using a critical point drying apparatus (Leica EM CPD030, Leica Microsystems, UK). Fragments were mounted on aluminum stubs, sputter-coated with gold (Desk IV, Denton Vacuum, USA) and examined in a scanning electron microscope (JSM6394LV, JEOL, Japan) operated at $12 \mathrm{kV}$.

\section{qPCR}

Frozen breast tissue from each rat was thawed and DNA was extracted from $25 \mathrm{mg}$ tissue previously homogenized with PBS. Frozen rat milk collected with cotton swabs was thawed and homogenized with $500 \mu \mathrm{l}$ PBS. Both tissue and liquid were extracted using Maxwell 16 Tissue DNA Purification kit (Promega, USA).

The qPCR was performed using 5'-nuclease (TaqMan, Thermo Fisher) assay and primers that amplified a sequence of the pathogen-specific Leptospira lipL32 gene [36], using the Applied Biosystems 7500 Fast Real-Time PCR instrument (Applied Biosystems, USA). For the standard curve, genomic DNA obtained from Leptospira serovar Copenhageni strain Fiocruz L1-130, the strain infecting Norway rats and humans in Salvador, was quantified using an ND-1000 spectrophotometer (Nanodrop Technologies, USA). Eight calibrating dilutions $\left[0-10^{7}\right.$ genome equivalents per millilitre $(\mathrm{GEq} / \mathrm{ml})]$ were prepared and served as reference values. The reaction mix consisted of $12.5 \mu 1$ PCR SuperMix-UDG (Invitrogen), $500 \mathrm{~nm}$ of forward and reverse primers, $100 \mathrm{nM}$ of probe, $5 \mu 1$ DNA extract and ultrapure water (Invitrogen) to a final volume of $25 \mu \mathrm{l}$. The amplification protocol consisted of $2 \mathrm{~min}$ at $50{ }^{\circ} \mathrm{C}$ and $10 \mathrm{~min}$ at $95^{\circ} \mathrm{C}$, followed by 40 cycles 
of denaturation at $95^{\circ} \mathrm{C}$ for $15 \mathrm{~s}$ and annealing/extension at $60^{\circ} \mathrm{C}$ for $1 \mathrm{~min}$. Cycle threshold $<40$ was treated as positive. For quality control, each reaction was run in duplicate and non-template controls were included in every column of 96 reaction plates. The rodent housekeeping gene glyceraldehyde-3-phosphate dehydrogenase (gapdh) was used as an internal control to monitor inhibition of PCR amplification and the efficiency of DNA extraction.

\section{Histopathological analyses of breast tissue samples}

For histopathological examination, breast tissue slides were stained with H\&E, Picrosirius (PIFG) and analysed by light microscopy. The main excretory duct, intralobular excretory duct, acinar tissue/ductal and intralobular stroma were evaluated. In these structures, morphological lesions were scored based on observations of acute and chronic inflammation, fibrosis, calcification, eosinophilic staining and fat content. The intensity score of the lesion was rated on a scale of $0-3(0=$ normal, $1=$ mild, $2=$ moderate, $3=$ severe $)$.

\section{Statistical analyses}

We performed descriptive analysis evaluating the proportion of positive animals for each sample and laboratory technique. Concordance between different techniques was assessed by the kappa index statistic.

\section{RESULTS}

\section{Samples}

Fifty-five lactating rats were caught during the study period. We obtained all tissue samples (kidney, breast and milk) from 24 lactating rats included in this study. These 24 animals did not differ in mass and age from other lactating rats captured but from which milk samples could not be obtained.

\section{Leptospira in kidney}

We defined carrier status by evaluating the presence of leptospires in kidney by IFA (Fig 1), IHC (Fig. 2) or qPCR. All 24 rats were positive by one or more tests (Table 1). All control samples from laboratory Wistar rats and wild rat samples incubated with normal rabbit serum were negative.

\section{Leptospira in milk}

Leptospires, as evaluated by IFA, were observed in 18 (75\%) expressed milk samples (10-20 $\mu$ l milk) from the 24 kidney-positive females (Fig. 1). Leptospires were sparsely distributed and not numerous in milk (Fig. 1d). The number of leptospires observed in milk ranged from 1 to 31 leptospires (mean 7.5) per four fields of view at a $\times 1000$ magnification. Four samples $(17 \%, 4 / 24)$ were positive by qPCR, with a range of $36-1484 \mathrm{GEq} / \mathrm{ml}$. All negative controls were negative. The internal control qPCR reaction using the gapdh gene were all positive, indicating that there was no inhibition or issues with the extraction that could explain the large number of negative samples obtained by qPCR compared to IFA.

\section{Leptospira in breast tissue}

Leptospires were sparse but clearly identifiable (in $67 \%$ of breast tissue samples by one or more tests (Fig. 1c). By specific test, leptospires were observed in $12(50 \%), 12(50 \%)$ and two $(8 \%)$ breast tissue samples by IFA, IHC and qPCR, respectively (Table 1, Figs $1 c, 2 d-f, 3 a-d$ ). The concordance between IFA and IHC findings was fair (kappa = $0 \cdot 61$ ). The two samples positive by qPCR indicated a bacterial burden ranging from 20 to 1519 GEq/ $\mathrm{mg}$, consistent with values obtained from milk. All breast tissue samples tested by qPCR were positive for the gapdh internal control gene. All the negative control breast samples from the two Wistar rats were negative by IFA, IHC and qPCR testing. The positive SEM from one of the four samples examined confirmed the presence of leptospires in breast tissue (Fig. 3). Attempts to isolate leptospires from breast samples resulted in contaminated cultures and contamination was not controlled by filtering and serial passage.

Of the 12 positive samples analysed by IHC, sparsely distributed leptospires with few organisms per microscopic field were detected within the mammary gland of $67 \%(8 / 12)$ rats and in $33 \%(4 / 12)$ of samples from the acinar/ductal region and connective tissue. The morphology of leptospires showed well-preserved size and morphological features. Leptospira with a clear helical morphology was more readily distinguished in breast tissue than in kidney tissue. However, visualization of bacteria by SEM showed aggregated leptospires, potentially in the form of biofilm within breast tissue and kidneys. 

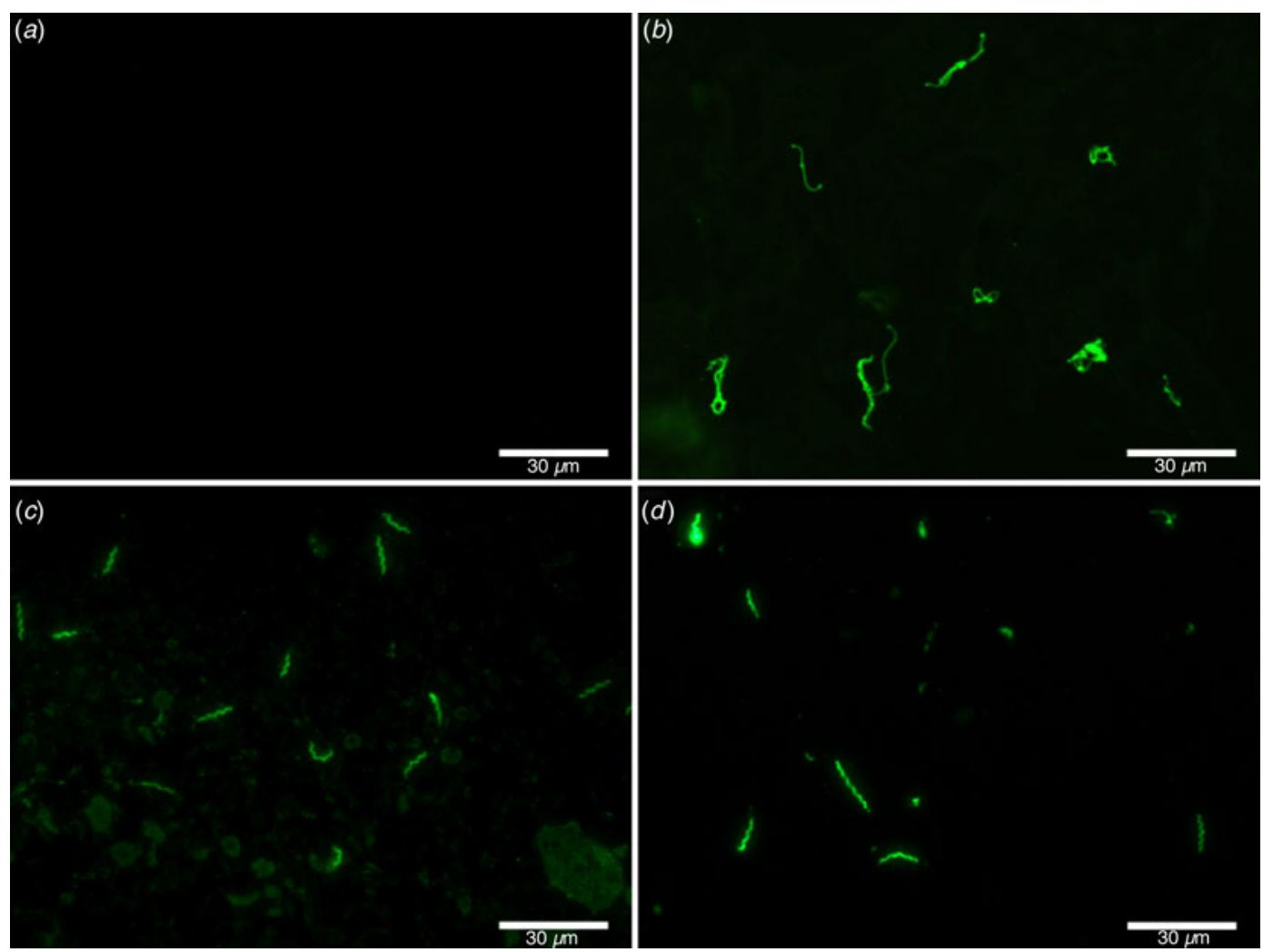

Fig. 1. Identification of Leptospira by indirect immunofluorescence in milk and breast slide impression samples obtained from chronically infected (kidney positive) wild-caught Rattus norvegicus. (a) Negative kidney control; (b) positive kidney control; (c) positive breast and $(d)$ positive milk. Magnification, $\times 1000$. Bars, $30 \mu \mathrm{m}$.

\section{Histopathological examination of breast tissue samples}

Staining by H\&E and PIFG identified mild to moderate lesions in breast tissue in $10(42 \%)$ rats (Table 2). Of these 10 animals, nine $(90 \%)$ had Leptospira in breast tissue or in milk detected by one or more assays. Lesions included: (a) enlarged main excretory duct, $(b)$ enlarged, calcification, and acute or chronic inflammation in the intralobular excretory duct, $(c)$ enlarged and acute inflammation of the acinar/ductal tissue comprising eosinophilic and fat secretion and (d) fibrosis in the intralobular stroma (Table 2). However, there were no statistical differences in the proportion of animals showing breast lesion when compared to Leptospira-positive and -negative females.

\section{DISCUSSION}

Lack of knowledge regarding the routes of intraspecific transmission of Leptospira in natural reservoirhost species, such as the Norway rat, are an obstacle to a complete understanding of the epidemiological factors underlying patterns of acquisition, maintenance and shedding of this spirochaete. Herein we describe for the first time the presence of pathogenic leptospires in the milk and breast tissue of lactating wild Norway rats demonstrated to be chronically infected by carriage of leptospires within their kidneys.

Although the outcomes of various assays varied, leptospires were demonstrated to be present by IFA testing of milk and breast tissue impressions, by IHC staining of breast tissue using pathogen-specific LipL32 antisera and by qPCR. Additionally, confirmation of breast colonization was demonstrated by visualization of clusters of leptospires by SEM.

Vertical or neonatal transmission of Leptospira has been suggested by findings of prevalence studies stratified by mass/age that indicate a proportion (up to $30 \%$ ) of the smallest juvenile rats are already infected by the time they leave their natal nest [15]. As the estimated age of these animals is $\sim 28$ days infection must have occurred in the nest at a minimum age of 18 days (A. Minter et al. unpublished data). During the postnatal period of 25-38 days [37] transmission from mother to 

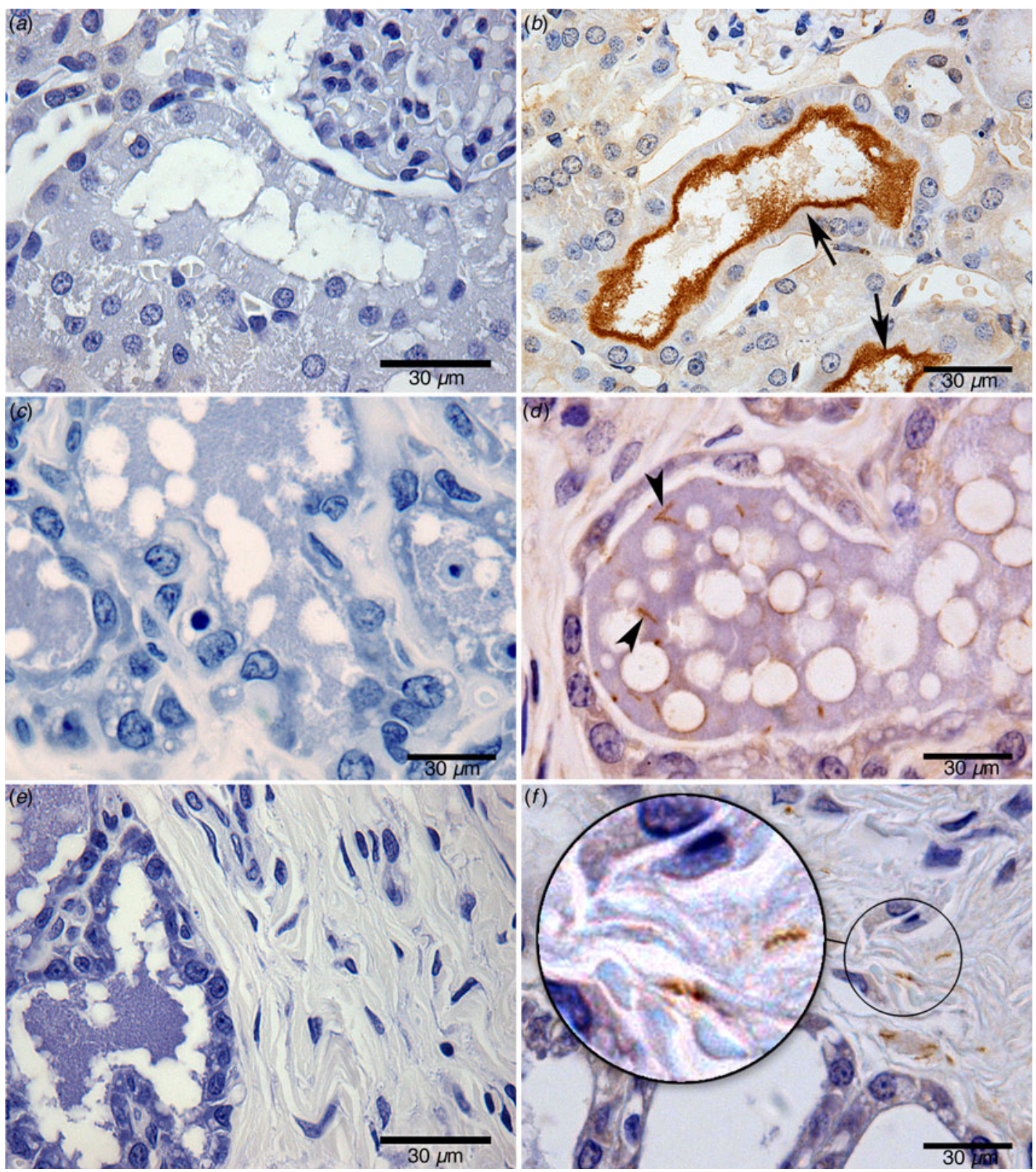

Fig. 2. Identification of Leptospira by immunohistochemistry: (a) negative kidney control; (b) renal tubule positive kidney control (arrow points to a cluster of leptospires); (c) negative mammary gland control; $(d)$ the mammary gland of a wild-caught chronically infected (kidney positive) Norway rat (arrow points to an individual leptospire; several are visible); (e) negative control in connective tissue of a breast sample; $(f)$ leptospires in connective tissue of a breast sample from a chronically infected (kidney positive) wild-caught Norway rat. Zoom highlights the morphological structure of leptospires, sharp helical structure; bar length, $30 \mu \mathrm{m}$.

offspring could occur via several routes, including in utero infection, breastfeeding, infectious saliva during grooming and female uro-genital cleansing of pups, urine of the dam or through fomites (e.g. contaminated nest material). The multitude of possible transmission routes limits the possibility to identify any specific route of vertical or neonatal transmission, although in utero transmission has been described [26, 27].
The presence of Leptospira in 67\% (8/12) of lumen of positive mammary glands sampled by IHC, indicates that pathogenic leptospires could readily be discharged with milk during suckling. The preference of leptospires for lumen compartments is commonly observed in the renal tubules of rat reservoirs [33]. Studies focusing on leptospiral colonization in renal tubules propose that preference for the lumen could 
Table 1. Results of laboratory tests for the presence of Leptospira in kidney, breast and milk samples in lactating urban slum rats (Rattus norvegicus)

\begin{tabular}{lllll}
\hline \hline & \multicolumn{4}{l}{ No. positive samples/no. total samples tested (\%) } \\
\cline { 2 - 5 } \cline { 2 - 5 } & Kidney & Breast & Milk & Breast \& milk \\
\hline Immunofluorescence (IFA) & $20 / 24(83)$ & $12 / 24(50)$ & $16 / 24(67)$ & $12 / 24(50)$ \\
Immunhistochemistry (IHC) & n.a. & $12 / 24(50)$ & n.a. & n.a. \\
Quantitative real-time polymerase chain reaction (qPCR) & $22 / 24(92)$ & $2 / 24(8)$ & $4 / 24(17)$ & $0(0)$ \\
IFA or IHC or qPCR & $24 / 24(100)$ & $16 / 24(67)$ & $18 / 24(75)$ & $14 / 24(58)$ \\
\hline \hline
\end{tabular}

n.a., Not applicable.
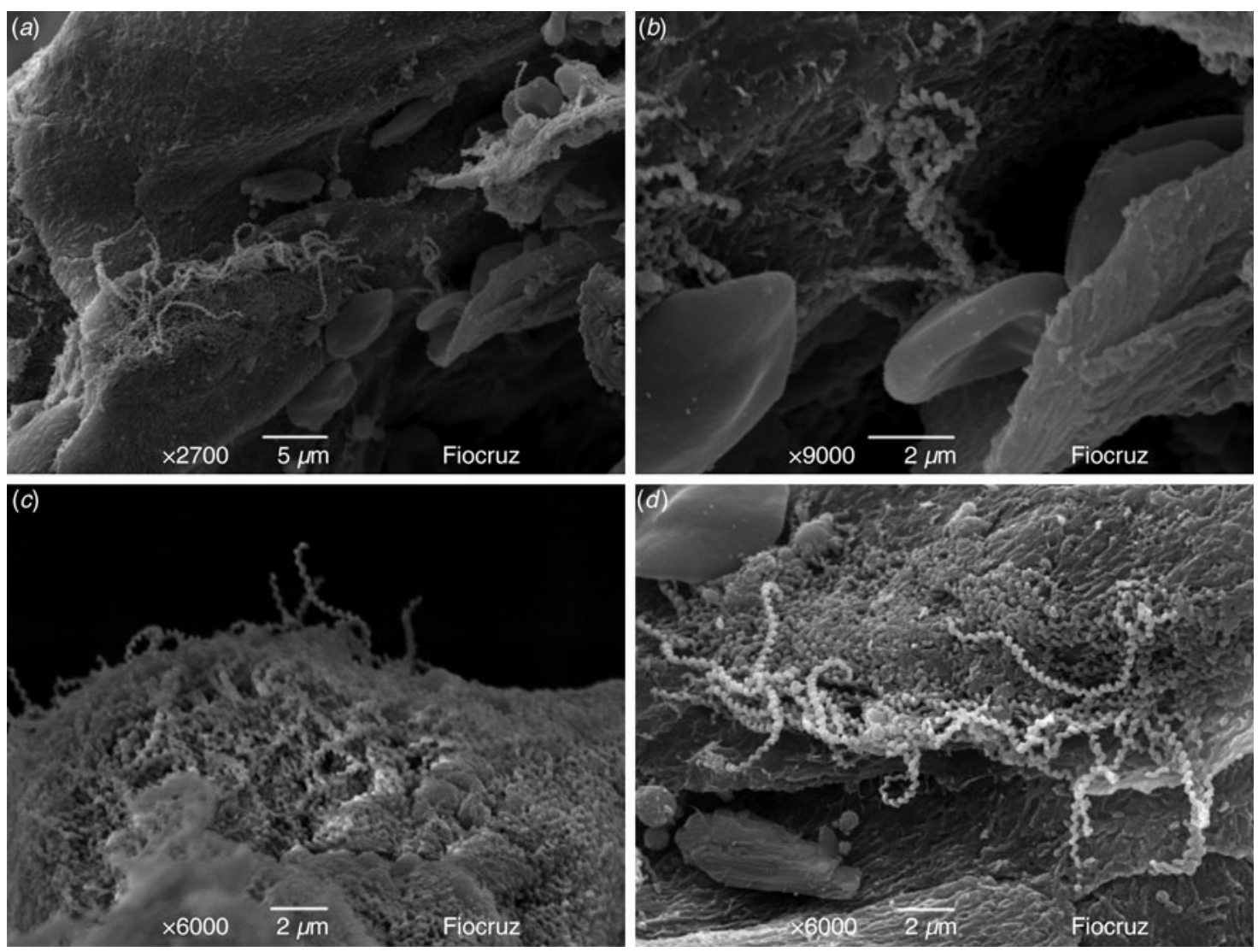

Fig. 3. Scanning electron microscopy reveals clusters of leptospires in breast tissue from a naturally infected wild-caught Rattus norvegicus. (a) Cluster of leptospires, (b) zoom of panel (a) showing visible erythrocytes in breast tissue; $(c, d)$ leptospires densely packed side by side.

be explained by the low antibody concentration in this tissue $[33,35]$. We also observed leptospires in the connective tissue of breast samples, and, although not determined, the titre of anti-Leptospira antibodies can be assumed to be low in this immunologically protected tissue. Furthermore, studies have shown that the mother can influence the immune state of pups, as well as the carrier state [38].
In mammary glands, leptospires were observed predominantly in free form with the length and helical morphology described for this bacterium. Relatively few organisms were present in any given microscopic field in both milk and breast tissue. However, as discussed below the small volumes of milk tested could translate into high levels of leptospire shedding during the course of breastfeeding. In addition, any 
Table 2. Histopathological alterations between positive and negative breast samples

\begin{tabular}{|c|c|c|c|}
\hline Alteration type & $\begin{array}{l}\text { Positive } \\
\text { breast } \\
(n=16)\end{array}$ & $\begin{array}{l}\text { Negative } \\
\text { breast } \\
(n=8)\end{array}$ & $\begin{array}{l}\text { Total } \\
(n=24) \\
(100 \%)\end{array}$ \\
\hline \multicolumn{4}{|l|}{ Main excretory duct } \\
\hline Enlarged & $16(100)$ & $8(100)$ & $24(100)$ \\
\hline Acute inflammation & $0(0)$ & $0(0)$ & $0(0)$ \\
\hline Chronic inflammation & $0(0)$ & $0(0)$ & $0(0)$ \\
\hline Fibrosis & $0(0)$ & $0(0)$ & $0(0)$ \\
\hline \multicolumn{4}{|l|}{$\begin{array}{l}\text { Intralobular excretor } \\
\text { duct }\end{array}$} \\
\hline Enlarged & $16(100)$ & $8(100)$ & $24(100)$ \\
\hline Acute inflammation & $3(19)$ & $1(13)$ & $4(17)$ \\
\hline Chronic inflammation & $1(6)$ & $0(0)$ & $1(4 \cdot 2)$ \\
\hline Mixed inflammation & $0(0)$ & $0(0)$ & $0(0)$ \\
\hline Fibrosis & $0(0)$ & $0(0)$ & $0(0)$ \\
\hline \multicolumn{4}{|l|}{ Acinar/ductal tissue } \\
\hline Enlarged & $16(100)$ & $8(100)$ & $24(100)$ \\
\hline Secretion eosinophilic & $16(100)$ & $6(75)$ & $22(92)$ \\
\hline Fat secretion & $16(100)$ & $4(50)$ & $20(83)$ \\
\hline Acute inflammation & $3(19)$ & $1(13)$ & $4(17)$ \\
\hline Chronic inflammation & $0(0)$ & $0(0)$ & $0(0)$ \\
\hline Mixed inflammation & $0(0)$ & $0(0)$ & $0(0)$ \\
\hline Calcification & $3(19)$ & $0(0)$ & $3(13)$ \\
\hline \multicolumn{4}{|l|}{ Intralobular stroma } \\
\hline Fibrosis & $6(37)$ & $1(13)$ & $7(29)$ \\
\hline Oedema & $0(0)$ & $0(0)$ & $0(0)$ \\
\hline Acute inflammation & $0(0)$ & $0(0)$ & $0(0)$ \\
\hline Chronic inflammation & $0(0)$ & $0(0)$ & $0(0)$ \\
\hline Bleeding & $0(0)$ & $0(0)$ & $0(0)$ \\
\hline Calcification & $0(0)$ & $0(0)$ & $0(0)$ \\
\hline
\end{tabular}

Values given are $n(\%)$.

immunological staining is limited to the restricted viewing of a limited number of sections and the visualization of bacteria by SEM clearly identified clusters of organisms, or potentially biofilm aggregates in breast tissue similar to observations from chronically infected kidneys [39, 40].

As mentioned above, the frequently reported findings that leptospires are cleared from all rat tissue, other than the kidney by $\sim 10$ days, our observations clearly suggest prolonged infection in breast tissue and shedding of organisms in milk. Each of the pregnant rats included in this study were kidney-positive females indicating that a carrier state had been achieved.

The presence of leptospires in wild Norway rat milk, although not previously described, is not biologically unique when considering other mammalian species. Cows infected with serovar Hardjo shed these bacteria in milk and mount an immune response that can result in mastitis [41]. Potential breastfeeding transmission of leptospirosis has been reported in a human newborn [20], and leptospires have also been isolated from human milk [42]. However, there is no evidence that infection from milk is a common route for transmission.

The number of leptospires in milk samples (range 1-31 per $\times 100$ field) could only be roughly approximated as milk samples were estimated to be less than $20 \mu$, and concentrations could not be estimated. However, qPCR results indicated similar leptospiral loads of $36-1484 \mathrm{GEq} / \mathrm{ml}$ in milk. When milk consumption is taken into account sucking pups could be exposed to high loads of leptospires prior to weaning. An increase in milk uptake occurs during the first 15 days of breastfeeding then declines when young are supplementing their diet with solid foods - preceding weaning at about day 27 [43, 44]. At postpartum day 15 dams can produce and accumulate up to $14 \mathrm{~g}$ (ml) of milk during each 3- to 4-h period prior to feeding pups [44]. A single pup in a litter of 10 pups (based on median embryo counts from $>100$ pregnant rats in Salvador, Brazil (J. A. Panti-May, unpublished data) could thus ingest $>8 \mathrm{ml}$ milk per day cumulatively containing hundreds $(\sim 300)$ or many thousands $(\sim 12000)$ of leptospires based on qPCR results. Furthermore, the cumulative volume of milk ingested over the entire course of breastfeeding would increase the exposure above tenfold.

The oral dose for infecting $R$. norvegicus is unknown. However, the intraperitoneal ID $_{50}$ for 4-dayold pups was $10^{2}$ (the study did not test lower doses) was far lower than the $10^{4}$ organisms required to infect adults, suggesting pups are more susceptible as mass alone cannot account for such a large difference [33, 45]. However, a previous study [45] indicated feasibility that an inoculum dose of Leptospira in the hundreds or thousands ingested through milk could cause infection.

The pathological consequences of leptospiral infection in breast tissue of Norway rats were minimal, and the pathogenic scores of infected tissue were no different from non-infected tissue. Of note, the presence of leptospires was not accompanied by inflammation and there were no significant pathological changes when breast tissue samples with presence and absence of leptospires were compared. These negative results suggest that colonization does not affect organ function and dilated acinar ducts and accumulation of hyaline material in the acini, compatible with milk, were present in infected animals. It is unlikely that colonized 
breasts would in any way inhibit the normal release of milk. In contrast, while the acute phase of clinical leptospirosis caused by serovar Hardjo in cows is usually subclinical, lactating cows show a number of pathological changes including agalactia ('milk drop syndrome') where small quantities of blood are shed in the milk. Agalactia is associated with a rapid drop in milk production, a soft flabby udder, febrile response and milk with appearance of yellow colostrum, thus affecting the quantity and quality of milk available to calves [23].

It is no surprise that the results from different diagnostic techniques varied, as none of these have been standardized for breast tissue. The presence of inhibitors or other material in milk could have contributed to low frequency of qPCR positive samples. Additionally, it was only possible to collect low volumes of milk from lactating rats. The IHC and IFA results indicated that leptospires were sparsely distributed in milk and breast tissue samples potentially limiting detection through qPCR sampling of small volumes of milk and breast tissue. However, SEM identified large aggregates of leptospires in breast tissue similar to observations of kidney proximal tubules [33]. As a consequence, this aggregation could impact the qPCR or other assays, since it may cause inhibition in the biofilm thus preventing detection.

Laboratory experiments and refinements to assays could shed light on the variation observed and confirm our findings of Leptospira in milk and breast tissue. Irrespective of the limitations mentioned above, our results, when considered in total, confirm the presence of leptospires in the milk and breast tissue of naturally infected Norway rats for the first time. Although leptospiral presence does not translate into demonstrating Leptospira transmission from dams to pups, the possibility of this transmission route deserves attention and additional studies. Characterization of potential transmission pathways is critical to understanding how leptospires are acquired and maintained in the Norway rat and other reservoir species and is essential for informing parameters used in mechanistic models of leptospirosis in rodent hosts [28].

\section{ACKNOWLEDGEMENTS}

The authors thank the staff of Zoonosis Control Centre, Salvador for their assistance in conducting the study. We also to thank Mayara Carvalho for her assistance with database processing and Kathryn
Hacker for review of the grammar. This work could not have been accomplished without the joint collaborative effort of the resident associations, community leaders and residents, which constitute the Urban Health Council of Pau da Lima. We thank the Global Leptospirosis Environmental Action Network (GLEAN). We also thank the Histotecnologia platforms and electron microscopy of the Gonçalo Moniz Research Center (FIOCRUZ-CPqGM-Bahia). This work was supported by the Oswaldo Cruz Foundation and Secretariat of Health Surveillance, Brazilian Ministry of Health, the National Institutes of Health (grants R01 AI052473, U01 AI088752, R01 TW009504, R25 TW009338 and R01 AI121207) and by the Wellcome Trust (102330/Z/13/Z).

\section{DECLARATION OF INTEREST}

None.

\section{REFERENCES}

1. Ko AI, Goarant C, Picardeau M. Leptospira: the dawn of the molecular genetics era for an emerging zoonotic pathogen. Nature Reviews Microbiology 2009; 7: 736-747.

2. Costa F, et al. Global morbidity and mortality of leptospirosis: a systematic review. PLoS Neglected Tropical Diseases. Published online: 17 September 2015. doi: 10.1371/journal.pntd.0003898.

3. Roczek A, et al. Severe course of rat bite-associated Weil's disease in a patient diagnosed with a new Leptospira-specific real-time quantitative LUX-PCR. Journal of Medical Microbiology 2008; 57: 658-663.

4. Lau CL, et al. Leptospirosis in American Samoa - estimating and mapping risk using environmental data. PLoS Neglected Tropical Diseases 2012; 6: e1669.

5. Mcbride AJA, et al. Leptospirosis. Tropical and Travelassociated Diseases 2005; 18: 376-386.

6. Felzemburgh RDM, et al. Prospective study of leptospirosis transmission in an urban slum community: role of poor environment in repeated exposures to the Leptospira Agent. PLoS Neglected Tropical Diseases 2014; 8: 1-9.

7. Ko AI, et al. Urban epidemic of severe leptospirosis in Brazil. Salvador Leptospirosis Study Group. Lancet 1999; 354: 820-825.

8. Sarkar U, et al. Population-based case-control investigation of risk factors for leptospirosis during an urban epidemic. American Journal of Tropical Medicine and Hygiene 2002; 66: 605-610.

9. Barocchi MA, et al. Identication of new repetitive element in Leptospira interrogans serovar Copenhageni and its application to PCR-based differentiation of Leptospira serogroups. Clinical Microbiology 2001; 39: 191-195.

10. De Faria MT, et al. Carriage of Leptospira interrogans among domestic rats from an urban setting highly 
endemic for leptospirosis in Brazil. Acta Tropica 2008; 108: $1-5$.

11. Allan KJ, et al. Epidemiology of leptospirosis in Africa: a systematic review of a neglected zoonosis and a paradigm for 'One Health' in Africa. PLoS Neglected Tropical Diseases. Published online: 14 September 2015. doi:10.1371/journal.pntd.0003899.

12. Easterbrook JD, et al. A survey of zoonotic pathogens carried by Norway rats in Baltimore, Maryland, USA. Epidemiology and infection 2007; 135: 1192-1199.

13. Himsworth CG, et al. The characteristics of wild rat (Rattus spp.) populations from an inner-city neighborhood with a focus on factors critical to the understanding of rat-associated zoonoses. PLoS ONE 2014; 9: 1-10.

14. Thiermann AB. The Norway rat as a selective chronic carrier of Leptospira icterohaemorrhagiae. Journal of Wildlife Diseases 1981; 17: 39-43.

15. Costa F, et al. Infections by Leptospira interrogans, Seoul virus, and Bartonella spp. among Norway rats (Rattus norvegicus) from the urban slum environment in Brazil. Vector Borne and Zoonotic Diseases 2014; 14: $33-40$.

16. Cox PJ, Twigg GI. Observations on kidney damage in hamsters following a non-icterohaemorrhagic form of disease resulting from infection by Leptospira interrogans serotype icterohaemorrhagiae. Journal of Comparative Pathology 1981; 91: 153-157.

17. Faine S, et al. Fatal congenital human leptospirosis. Zentralblatt fur Bakteriologie, Mikrobiologie und Hygiene 1984; 257: 548.

18. Shaked Y, et al. Leptospirosis in pregnancy and its effect on the fetus: case report and review. Clinical Infectious Diseases 1993; 17: 241-243.

19. Poonacha KB, et al. Leptospirosis in equine fetuses, stillborn foals, and placentas. Veterinary Pathology 1993; 30: 362-369.

20. Bolin CA, Koellner P. Human-to-human transmission of Leptospira interrogans by milk. Infectious Diseases 1988; 158: 246-247.

21. Harrison NA, Fitzgerald WR. Leptospirosis - can it be a sexually transmitted disease? Postgraduate Medical Journal 1988; 64: 163-164.

22. Hamond C, et al. Presence of leptospiral DNA in semen suggests venereal transmission in horses. Journal of Equine Veterinary Science 2013; 33: 1157-1159.

23. Higgins RJ, et al. Mastitis and abortion in dairy cattle associated with Leptospira of the serotype hardjo. Veterinary Record 1980; 107: 307-310.

24. Leon-Vizcaino L, Hermoso MM, Garrido F. Incidence of abortions caused by leptospirosis in sheep and goats in Spain. Comparative Immunology, Microbiology and Infectious Diseases 1987; 10: 149-153.

25. Lahiri MN. On the foetal infection by I. icterohaemorrhagiae in a rat. Indian Journal of Medical Research 1941; 29: 685-688.

26. Schnurrenberger PR, Hanson LE, Martin RJ. Leptospirosis: long-term surveillance on an Illinois farm. American Journal of Epidemiology 1970; 92: 223-239.

27. Ward TG, Turner TB. Natural infection of the fetus with Leptospira Icterohemorrhagiae in a wild rat.
American Journal of Tropical Medicine and Hygiene 1940; 1: 727-730.

28. Holt J, Davis S, Leirs H. A model of Leptospirosis infection in an African rodent to determine risk to humans: seasonal fluctuations and the impact of rodent control. Acta Tropica 2006; 99: 218-225.

29. Reis RB, et al. Impact of environment and social gradient on Leptospira infection in urban slums. PLoS Neglected Tropical Diseases 2008; 2: 11-18.

30. Costa F. et al. Influence of household rat infestation on Leptospira transmission in the urban slum environment. PLoS Neglected Tropical Diseases 2014; 8: 1-8.

31. Costa F, et al. Patterns in Leptospira shedding in Norway rats (Rattus norvegicus) from Brazilian slum communities at high risk of disease transmission. PLOS Neglected Tropical Diseases 2015; 9: 1-14.

32. Chagas-Junior AD, et al. An imprint method for detecting leptospires in the hamster model of vaccinemediated immunity for leptospirosis. Journal of Medical Microbiology 2009; 58: 1632-1637.

33. Athanazio DA, et al. Rattus norvegicus as a model for persistent renal colonization by pathogenic Leptospira interrogans. Acta Tropica 2008; 105: 176-180.

34. Murray GL, et al. Major surface protein LipL32 is not required for either acute or chronic infection with leptospira interrogans. Infection and Immunity 2009; 77: 952-958.

35. Faine S, Adler B, Perolat P. Leptospira and Leptospirosis, 2nd edn. Melbourne, Australia: MedSci, 2000.

36. Stoddard RA, et al. Detection of pathogenic Leptospira spp. through TaqMan polymerase chain reaction targeting the LipL32 gene. Diagnostic Microbiology and Infectious Disease 2009; 64: 247-255.

37. Calhoun JB. The Ecology and Sociology of the Norway rat. Bethesda, MD: University of California, 1963.

38. Birnbaum S, Shenberg E, Torten M. Influence of maternal antibodies on the epidemiology of leptospiral carrier state in mice. American Journal of Epidemiology 1972; 96: $313-317$.

39. Agudelo-Flórez P, et al. Histopathological kidney alterations in rats naturally infected with Leptospira. Biomédica 2013; 33: 82-88.

40. Ristow $\mathbf{P}$, et al. Biofilm formation by saprophytic and pathogenic leptospires. Microbiology (Reading, England) 2008; 154: 1309-1317.

41. Ellis WA, et al. Bovine leptospirosis: infection by the Hebdomadis serogroup and mastitis. Veterinary Record 1976; 99: 368-370.

42. Chung HL et al. Transplacental or congenital infection of leptospirosis Clinical and Experimental observations. Chinese Medical Journal 1963; 82: 777-782.

43. Galef JGB. The Ecology of Weaning. Parental Care in Mammals. New York: Springer.

44. Thiels E, Cramer CP, Alberts JR. Behavioral interactions rather than milk availability determine decline in milk intake of weanling rats. Physiology \& Behavior 1988; 42: 507-515.

45. Muslich LT, et al. Characterization of Leptospira infection in suckling and weaning rat pups. Comparative Immunology, Microbiology and Infectious Diseases 2015; 38: 47-55. 